\title{
Diversiteit in bestuurskundig perspectief
}

\author{
Saniye Çelik
}

In de praktijk blijken diversiteitsinterventies in publieke organisaties niet altijd effectief te zijn. Een mogelijke oorzaak is dat er geen of weinig match is tussen perspectieven van publieke organisaties op diversiteit en de ingezette interventies. Dit artikel biedt een overzicht van de achterliggende rationales voor diversiteitsbeleid en bespreekt de perspectieven op diversiteit uit de diversiteitsliteratuur, HRM en bestuurskundige literatuur en hoe deze overlappen, elkaar aanvullen en van elkaar verschillen. Wat deze perspectieven met elkaar gemeen hebben, is dat ze alle de meerwaarde van diversiteit benadrukken. In de diversiteitsliteratuur ligt het accent op de vier invalshoeken gelijkheid, legitimiteit, creativiteit en arbeidsmarkt. In de HRM-literatuur staat het managen van verschillen centraal. In de bestuurskunde is er een verschuiving te zien van actieve representatie door individuen naar het verbinden door alle medewerkers. Verder wint het verbindingsperspectief steeds meer aan belang in het publieke domein, omdat het voorkomt dat er een kloof ontstaat tussen overheid en burger. Dit perspectief benadrukt het belang van de langetermijnrelatie met burgers om het vertrouwen van burgers in de overheid te versterken voor het realiseren van maatschappelijke opgaven. Het maakt diversiteit een taak voor alle medewerkers, niet alleen voor Hassan en Havva, maar ook voor Hans en Hanna.

\section{Inleiding}

Diversiteitsbeleid bij de overheid heeft een lange historie. Al ruim dertig jaar investeert de overheid in het diverser maken en houden van de personeelssamenstelling. Intussen is Nederland sociaal-cultureel en demografisch aanzienlijk veranderd. De noodzaak voor de overheid om verschillen in de samenleving te verbinden of daarop in te spelen is almaar groter geworden. Het bevorderen van diversiteit in publieke organisaties wordt gezien als een manier om organisatiedoelen te realiseren (SER, 2009). De gangbare definitie van diversiteit is: alle zichtbare en onzichtbare kenmerken waarin mensen van elkaar verschillen. Zichtbare kenmerken zijn bijvoorbeeld geslacht en etniciteit. Onzichtbare kenmerken zijn normen, waarden, overtuigingen, behoeften, competenties, werkstijlen en karaktereigenschappen (Harrison \& Klein, 2007). Het publieke debat over diversiteit binnen de publieke sector heeft doorgaans betrekking op gender en etnische

* Dr. S Çelik (celik.s@hsleiden.nl) is bestuurskundige en lector Diversiteit aan de Hogeschool Leiden. $\mathrm{Zij}$ is de twee anonieme referenten van Bestuurskunde zeer erkentelijk voor hun commentaar op een eerdere versie van dit artikel. 
herkomst. Publieke organisaties zoals de rijksoverheid, gemeenten, politie en het hoger onderwijs voeren diversiteitsbeleid omdat hun bestuurders ervan overtuigd zijn dat zo'n beleid iets wezenlijks toevoegt aan het oplossen van maatschappelijke vraagstukken. We noemen deze meerwaarde ook wel 'de business case van diversiteit' (Çelik, 2016). Vanuit deze meerwaarde hebben publieke organisaties en politici allerlei beleidsvoornemens en zetten diversiteitsinterventies in. ${ }^{1}$

In de praktijk spreekt men veel over het belang van diversiteit voor publieke organisaties en de duiding ervan varieert nogal. Soms gaat het om etnische groepen, soms ligt de focus op vrouwen in hogere functies (Rijksoverheid, 2018). Waar het in de praktijk nog aan ontbreekt, is een overzicht van motieven om diversiteit in publieke organisaties inzichtelijk te maken. Inzicht in de motieven kan helpen bij een adequate beleidsontwikkeling en het kiezen van interventies die een logische afgeleide zijn van het perspectief. Wanneer bijvoorbeeld de rijksoverheid met diversiteit de organisatie inventiever wil maken, dan passen daar andere interventies bij dan het hanteren van streefcijfers. Een mismatch tussen de motieven en de interventies kan ten koste gaan van de effectiviteit van interventies (Tanghe, Van der Zee, \& Postmes, 2010; Çelik, 2016). Kennis over de motieven is tevens van belang voor de ontwikkeling van gerichte interventies. Want de motieven geven richting aan interventies die organisaties kiezen. Binnen de publieke sector is nauwelijks bekend in hoeverre de ingezette diversiteitsinterventies bijgedragen hebben aan de organisatiedoelen (Frouws \& Buiskool, 2010; Verbeek, 2012). Over de effecten van de interventies weten we weinig. Onderzoek laat wel een discrepantie zien tussen de motieven van organisaties om werk te maken van diversiteit en de interventies die worden ingezet (Çelik, 2016, pp. 184-185). Wanneer bijvoorbeeld een organisatie als motief het bevorderen van innovatieve ideeën in de organisatie heeft, dan passen daar eerder interventies bij als co-creatiesessies met medewerkers dan het hanteren van streefcijfers voor meer vrouwen of mensen met een migratieachtergrond. Dit artikel beschrijft de motieven ofwel diversiteitsperspectieven in verschillende wetenschappelijke disciplines, hoe zij met elkaar samenhangen en wat ze kunnen betekenen als basis voor beleid in een publieke context. Het thema diversiteit komt regelmatig aan bod in de literatuur over diversiteit, HRM en bestuurskunde. Hierna volgt een verhandeling van de diversiteitsperspectieven uit de theoretische invalshoeken en wat de onderlinge verschillen en raakvlakken zijn.

\section{Diversiteitsliteratuur}

Verschillende wetenschappelijke disciplines zetten uiteen waarom organisaties diversiteit bevorderen (Ely \& Thomas, 2001; Kirton \& Greene, 2010). Ely en Thomas (2001) presenteren drie verschillende diversiteitsperspectieven. Elk perspectief geeft een reden voor het streven naar een divers personeelsbestand. De

1 Wetgevingsoverleg begroting Binnenlandse Zaken. Debat van de vaste commissie voor Binnenlandse Zaken (Tweede Kamer der Staten-Generaal), 16 oktober 2018. Kamerstukken II 2017/18, $35000,7$. 
drie zijn: discrimination \& fairness (het gelijkheidsperspectief), access \& legitimacy (het legitimiteitsperspectief) en integration \& learning (het creativiteitsperspectief). Andere auteurs voegen hier later het arbeidsmarktperspectief aan toe (Ashikali, Erradouani \& Groeneveld, 2013; Kochan, Bezrukova, Ely, Jackson, Joshi, Leonard et al., 2003).

\section{Gelijkheid}

Het morele uitgangspunt van het gelijkheidsperspectief - ook wel rechtvaardigheidsperspectief genoemd - is dat eenieder gelijk is en ook zo behandeld moet worden. Het richt zich op het bieden van gelijke kansen voor werving en promotie, en op het tegengaan van vooroordelen en discriminatie (Selden \& Selden, 2001). Organisaties die op basis hiervan handelen, doen dit vanuit de morele plicht een afspiegeling te zijn van de maatschappij (Saltzstein, 1979). Het doelgroepenbeleid in de publieke sector vanaf de jaren tachtig is vanuit deze visie op diversiteit ontwikkeld en heeft nog steeds de overhand. Zo is de focus blijven liggen op het beperken van discriminatie en het vergroten van de etnisch-culturele diversiteit binnen de overheid (Regeerakkoord, 2017, p. 54).

Niet zo verwonderlijk, want het gelijkheidsdenken is in Nederland expliciet aanwezig en vastgelegd in artikel 1 van de Grondwet (antidiscriminatie). De overheid wil vanuit haar maatschappelijke verantwoordelijkheid én als grootste werkgever in Nederland (één miljoen werknemers) een voorbeeld zijn voor de private sector, teneinde rechtvaardigheid en emancipatie te stimuleren (Çelik, 2016). Diversiteit ziet men als een substantiële waarde; de meerwaarde wordt niet afhankelijk gemaakt van de verwachte positieve effecten voor de organisatie. Voorbeelden van beleidsinterventies op basis van dit perspectief zijn aangepaste wervings- en selectiemethoden, zoals anoniem solliciteren, en het invoeren van quota om de instroom en doorstroom van specifieke groepen, zoals vrouwen en mensen met een migratieachtergrond, te bevorderen.

\section{Legitimiteit}

Dit perspectief gaat uit van de kansen die diversiteit biedt voor de markt, zoals het vergaren van kennis over en aansluiting vinden bij verschillende (etnische) groepen in de samenleving. Men beseft dat de markt waarop organisaties actief zijn steeds diverser wordt. Wie de eigen diversiteit vergroot, krijgt een betere toegang tot de beoogde groepen, kan beter aansluiten bij hun wensen en behoeften, en versterkt zijn legitimiteit (Ely \& Thomas, 2001; Herring, 2009). Een veelvoorkomende interventie in de praktijk, gestoeld op dit perspectief, is het werven met specifieke recruiters om bepaalde doelgroepen te bereiken (Çelik, 2016). De politie is zo'n organisatie die specifieke recruiters heeft aangesteld om verschillende groepen te interesseren voor het politiewerk. ${ }^{2}$ Dat gebeurt vanuit de gedachte dat mensen met dezelfde achtergrond elkaar begrijpen en daardoor goed met elkaar communiceren. Organisaties die aansluiting creëren tussen medewerkers en afnemers hopen op economische voordelen voor de organisatie. Maar

2 Politie. Brief van de minister van Veiligheid en Justitie aan de Voorzitter van de Tweede Kamer der Staten-Generaal. Kamerstukken II 2016/17, 29628, 711. 
vaak worden uitsluitend de afdelingen die in direct contact staan met de klanten divers gemaakt. Daarmee beperkt de meerwaarde van diversiteit zich tot de desbetreffende afdeling en dringt deze niet door tot de diepere lagen van de organisatie (Ely \& Thomas, 2001).

\section{Creativiteit}

Verschillen zijn goed voor creativiteit en innovatie, ze leveren betere producten en diensten op, en verbeteren daardoor de prestaties van een organisatie (Van Knippenberg \& Schippers, 2007). Dit zijn de gedachten achter het creativiteitsperspectief. Diversiteit wordt gezien als een interne bron van productiviteit. Kennis, inzichten en vaardigheden van medewerkers uit verschillende etnische groepen (zowel meerderheid als minderheid) worden in de praktijk benut. Organisaties die streven naar diversiteit vanuit dit perspectief gebruiken de kennis, inzichten, competenties en ervaringen die medewerkers hebben meegekregen door hun achtergrond om de eigen werkprocessen, cultuur en kerntaken te herevalueren en eventueel aan te passen. Verschillen in etnische achtergrond en de verschillende visies die hieruit ontspruiten, worden gezien als leermomenten voor nieuwe inzichten. Medewerkers worden gewaardeerd, gerespecteerd en aangemoedigd zich te profileren als lid van hun groep (Ely \& Thomas, 2001). Het creativiteitsperspectief is uiterst nuttig voor wie een inclusieve organisatiecultuur wil bevorderen. Inclusiviteit betekent hier dat alle werknemers zich betrokken voelen bij de organisatie, ongeacht leeftijd, sekse of culturele achtergrond, en gewaardeerd worden om wie ze zijn (Shore et al., 2011). Een interventie vanuit dit perspectief is het zodanig samenstellen van selectieteams dat de kwaliteiten van sollicitanten uit diverse achtergronden worden herkend (Çelik, 2016). Deze interventie komt bijvoorbeeld voor bij de rijksoverheid. Om bias bij selecties te voorkomen worden daarnaast selecteurs extra getraind. ${ }^{3}$ Ook leiderschapstrainingen voor het bevorderen van inclusie op de werkvloer kunnen vanuit dit perspectief worden geïnitieerd. ${ }^{4}$

\section{Arbeidsmarkt}

De motieven van organisaties om te streven naar diversiteit van het personeelsbestand vanuit dit perspectief zijn legio, deels overlappen ze elkaar. Ten eerste voelen publieke organisaties de noodzaak te anticiperen op (komende) personeelstekorten als gevolg van vergrijzing en ontgroening van het huidige personeel (Kochan et al., 2003; Ashikali, Erradouani, \& Groeneveld, 2013). Ten tweede willen ze het menselijk kapitaal beter benutten. Publieke organisaties beschouwen het als een uitdaging, door te verwachten tekorten op de arbeidsmarkt, om voldoende gekwalificeerd personeel te binden aan en te boeien voor de overheid (Kwakkelstein \& Roelse, 2011). Ten derde werkt een diverse opbouw van het personeelsbestand positief bij het aantrekken van een diversiteit aan medewerkers

3 Vernieuwing van de Rijksdienst. Brief van de minister van Binnenlandse Zaken en Koninkrijksrelaties aan de Voorzitter van de Tweede Kamer der Staten-Generaal. Kamerstukken II 2017/18, 31490, 239.

4 Idem. 
(Van Hooft, 2005). Ten vierde kan het streven voortkomen uit de wens de organisatie te profileren als aantrekkelijke werkgever, en divers personeel te willen vinden en behouden (Çelik, Vos, \& De Vries, 2014). Het arbeidsmarktperspectief krijgt in de praktijk onder meer concreet vorm door het creëren van stageplaatsen voor jongeren. ${ }^{5}$

\section{HRM-perspectief}

In de HRM-literatuur was er over het algemeen weinig aandacht voor sociaaldemografische verschillen tussen mensen. In de praktijk kwam diversiteit steeds meer op de HRM-agenda van publieke organisaties (Van der Meer \& Dijkstra, 2013). Omdat HRM alles te maken heeft met het in dienst nemen en houden van medewerkers, ontstond er binnen de HRM-afdelingen aandacht voor de uitwerking van het beleid voor medewerkers met verschillende achtergronden. Organisaties zagen diversiteit steeds vaker als belangrijke human resources (Steijn \& Groeneveld, 2013). En zo werd diversiteit in toenemende mate benaderd als een managementopgave. Dit heeft ertoe geleid dat in de wetenschap diversiteit steeds meer als onderdeel van HRM wordt bestudeerd. In de HRM-literatuur ligt het accent op het managen van verschillen in de organisatie voor het verbeteren van de prestaties (Boselie, 2014). In de praktijk zijn de lijnmanagers steeds meer verantwoordelijk geworden voor diversiteitsmanagement op de werkvloer.

Het HRM-perspectief vertoont raakvlakken met het creativiteitsperspectief uit de diversiteitsliteratuur; echter bij diversiteitsmanagement ligt de nadruk meer op het managen van de verschillen. Diversiteitsmanagement wordt in de HRM-literatuur gedefinieerd als 'het bevorderen van een divers personeelsbestand en het managen van verschillen voor het behalen van betere organisatieprestaties' (Pitts, 2009). De nadruk ligt op alle manieren waarop individuen van elkaar kunnen verschillen en hoe deze verschillen te benutten zijn (Kellough \& Naff, 2004). Het omgaan met verschillen tussen medewerkers als onderdeel van leiderschapsprogramma's is een voorbeeld van een interventie die hierop aansluit. Een illustratie van een interventie voor het managen van verschillen is te zien bij de rijksoverheid. Om ruimte voor verschillen op de werkvloer te stimuleren is het thema een onderdeel van de leiderschapsvisie en van managementprogramma's bij de departementen. ${ }^{6}$

\section{Bestuurskundig perspectief}

In de bestuurskunde wordt een relatie gelegd met de representatie van minderheden in overheidsorganisaties (Von Maravić, Peters, \& Schröter, 2013), wat is

5 Arbeidsmarktbeleid. Brief van de staatssecretaris van Sociale Zaken en Werkgelegenheid aan de Voorzitter van de Tweede Kamer der Staten-Generaal. Kamerstukken II 2017/18, 29544, 834.

6 Vernieuwing van de Rijksdienst. Brief van de minister van Binnenlandse Zaken en Koninkrijksrelaties aan de Voorzitter van de Tweede Kamer der Staten-Generaal. Kamerstukken II 2017/18, 31490, 239 . 
terug te voeren op het klassieke thema van representatieve bureaucratie (Bailey, 2004). Dit impliceert dat bestuurders beter kunnen inspelen op de diversiteit in de samenleving als het ambtelijk apparaat een weerspiegeling vormt van de bevolking. Daarnaast is er in de bestuurskunde in toenemende mate aandacht voor de verbinding met de samenleving als een nieuw perspectief (Çelik, 2016).

\section{Representatieve bureaucratie}

Representatieve bureaucratie stelt dat de weerspiegeling van de demografische kenmerken van de bevolking in het personeelsbestand van de overheid bijdraagt aan haar legitimiteit en effectiviteit. Dit perspectief kent overeenkomsten met het gelijkheidsperspectief en het legitimiteitsperspectief uit de diversiteitsliteratuur. Representatieve bureaucratie maakt onderscheid tussen passieve en actieve representatie (Mosher, 1968; Coleman Selden, Brudney, \& Kellough, 1998; Dolan \& Rosenbloom, 2003). Passieve representatie heeft betrekking op de achtergrondkenmerken van het ambtelijk apparaat en verwijst naar de wijze waarop dat demografisch een afspiegeling vormt van de samenstelling van de bevolking (Groeneveld \& Steijn, 2013). Passieve representatie raakt het gelijkheidsperspectief. Ze benadrukken allebei het bieden van gelijke kansen. Passieve representatie verandert in actieve representatie wanneer overheidsbesluiten ook de waarden van de minderheidsgroep weerspiegelen (Selden, Brudney, \& Kellough, 1998). Actieve representatie verwijst naar de mate waarin ambtenaren als pleitbezorgers optreden van de belangen van specifieke groepen waartoe zij zelf behoren. De veronderstelling is dat de ambtenaar in zijn of haar functioneren de belangen behartigt en de wensen vervult van de groep die hij of zij vertegenwoordigt. De vertegenwoordiging van de verschillende bevolkingsgroepen maakt het mogelijk dat hun waarden en normen een rol spelen bij de beleidsontwikkeling. Het beleid sluit dan beter aan bij wat er leeft onder de bevolking en wordt door alle bevolkingsgroepen beter geaccepteerd dan wanneer hun stem niet doorklinkt (Sowa \& Selden, 2003). Actieve representatie vertoont gelijkenis met het legitimiteitsperspectief uit de diversiteitsliteratuur.

\section{Verbindingsperspectief}

Het verbindingsperspectief vertoont raakvlakken met het legitimiteitsperspectief en representatieve bureaucratie. Deze invalshoeken gaan er allemaal van uit dat de afspiegeling van demografische kenmerken van de bevolking in de personeelssamenstelling bijdraagt aan de effectiviteit van de overheid. De onderliggende aanname is dat met diversiteit beter aangesloten kan worden bij de wensen en behoeften uit de samenleving. Het verbindingsperspectief gaat echter verder en ziet het als een taak van alle medewerkers binnen de overheid om duurzame verbindingen aan te gaan met burgers teneinde maatschappelijke vraagstukken op te kunnen lossen (Çelik \& Çelik, 2017). Het verbindingsperspectief benadrukt de noodzaak actief te investeren in de langetermijnrelatie met de burger. Een opvallend onderscheid met de andere invalshoeken is dit: het omgaan met de verschillen is een issue van alle medewerkers, ongeacht hun etnische achtergrond. Allen worden geacht verbindingen te leggen met de diversiteit aan burgers in de samenleving. Dit perspectief uit zich in het centraal stellen van de voorbeeldfunctie, de 
dienstbaarheid van de overheid en daarmee samenhangend de tevredenheid van de burgers (Çelik, 2016). Het is een nieuw perspectief in de bestuurskunde, dat steeds meer aandacht krijgt, vooral dankzij enkele actuele maatschappelijke ontwikkelingen. Denk aan de participatiesamenleving, die nastreeft dat de overheid en de burgers met elkaar in verbinding staan en in gezamenlijkheid het publieke belang dienen. Of aan de toenemende nadruk op het belang van een responsieve overheid, die het belang van burgers centraal stelt en hoogwaardige dienstverlening aan hen biedt (Bekkers, 2007; Rob, 2015; Çelik \& Hopman, 2018). Responsiviteit gaat in de kern om het vertrouwen van de burgers in de overheid en vormt een belangrijke waarde die ten grondslag ligt aan het verbindingsperspectief. Wanneer het vertrouwen van burgers in het bevoegd gezag toeneemt, ziet iedere burger het als zijn of haar overheid. Laatstgenoemde kan zo beter haar verbindende rol vervullen en haar maatschappelijke opgaven realiseren. Op deze manier voorkomt de overheid dat bepaalde groepen zich terugtrekken uit de samenleving en zich tegen haar keren (Rob, 2015; Çelik, 2016). Bij het verbindingsperspectief is het object de relatie en de interactie tussen de overheid en de burger, waardoor burgers meer betrokken worden bij het oplossen van maatschappelijke vraagstukken. Een voorbeeld dat past in het verbindingsperspectief is de inzet van buurtvaders ter verhoging van de veiligheid in de wijk, maar ook de toenemende co-creatie met burgers bij de ontwikkeling van beleid. (Çelik, 2018). Ook het stimuleren van het verbindend vermogen, immers een belangrijke kerncompetentie voor alle medewerkers, is afgeleid van dit perspectief. Het talent om te kunnen verbinden is tegenwoordig steeds vaker een belangrijke competentie in een functieomschrijving.

Tabel 1 geeft een overzicht van de diversiteitsperspectieven en de onderliggende motieven. Deze kunnen helpen bij de vorming van beleid en interventies in het publieke domein.

\section{Theoretische samenhang}

Verscheidene theorieën over diversiteit kunnen als kader en inspiratiebron dienen voor organisaties om ermee aan de slag te gaan. Het zijn perspectieven op diversiteit die weliswaar verschillend zijn, maar in bepaalde opzichten met elkaar samenhangen en elkaar aanvullen. In de praktijk kunnen de perspectieven naast elkaar bestaan. Het ene sluit het andere niet uit. De belangrijkste overeenkomst van de perspectieven is dat ze te karakteriseren zijn als de businesscase van diversiteit, omdat ze diversiteit verbinden aan de doelen van de organisatie. In de diversiteitsliteratuur ligt het accent op de vier invalshoeken: gelijkheid, legitimiteit, creativiteit en arbeidsmarkt. Het gelijkheidsperspectief wordt niet getypeerd als een businesscasebenadering. Dit perspectief gaat weliswaar niet over de meerwaarde van diversiteit voor publieke organisaties, maar wordt wel veelvuldig gebruikt als argument voor de voorbeeldrol van de overheid. De tweede invalshoek - legitimiteit - richt zich, zoals de naam al zegt, op het vergroten van de legitimiteit en de herkenbaarheid van de organisatie, zodat deze beter kan inspe- 


\section{Tabel 1 Diversiteitsperspectieven en motieven}

\begin{tabular}{|c|c|c|}
\hline Disciplines & Perspectieven & Motieven \\
\hline \multirow[t]{4}{*}{$\begin{array}{l}\text { Diversiteitslitera- } \\
\text { tuur }\end{array}$} & Gelijkheid & $\begin{array}{l}\text { Gelijke kansen en het tegengaan van discriminatie } \\
\text { van minderheidsgroepen }\end{array}$ \\
\hline & Legitimiteit & $\begin{array}{l}\text { Aansluiting vinden bij verschillende groepen in de } \\
\text { samenleving en zo het contact met de samenleving } \\
\text { vergroten en een bredere groep bereiken }\end{array}$ \\
\hline & Creativiteit & $\begin{array}{l}\text { Diversiteit als waardevolle bron voor nieuwe } \\
\text { inzichten voor betere besluitvorming en/of presta- } \\
\text { ties } \\
\text { Integreren van verschillen in de organisatiecultuur } \\
\text { en deze benutten }\end{array}$ \\
\hline & Arbeidsmarkt & $\begin{array}{l}\text { Inspelen op grote vervangingsvraag en breed } \\
\text { arbeidsaanbod } \\
\text { Verbeteren van het imago als aantrekkelijke werk- } \\
\text { gever }\end{array}$ \\
\hline HRM & $\begin{array}{l}\text { Diversiteit als manage- } \\
\text { mentopgave }\end{array}$ & $\begin{array}{l}\text { Managen van verschillen voor het behalen van } \\
\text { betere organisatieprestaties }\end{array}$ \\
\hline \multirow[t]{2}{*}{ Bestuurskunde } & Actieve representatie & $\begin{array}{l}\text { Legitimiteit van de organisatie in de samenleving } \\
\text { Vertegenwoordiging van waarden in de samenleving } \\
\text { in besluitvormingsprocessen }\end{array}$ \\
\hline & Verbinding & $\begin{array}{l}\text { Verwezenlijken van maatschappelijke opgaven } \\
\text { Verbindend vermogen van alle medewerkers } \\
\text { Verkleinen van de kloof overheid-samenleving } \\
\text { Verduurzamen relatie met burgers }\end{array}$ \\
\hline
\end{tabular}

len op de behoeften van burgers. Het arbeidsmarktperspectief kan hier deels onder worden geschaard; het komt voort uit de behoefte van organisaties om aan te sluiten bij de veranderende arbeidsmarkt. Het uitgangspunt bij creativiteit is dat diversiteit bijdraagt aan een groter scheppend en vernieuwend vermogen in de organisatie en daarmee haar prestaties stimuleert. Hier ligt een relatie met diversiteitsmanagement uit de HRM-literatuur, die een verbinding legt met het inzetten van medewerkers en de doelen van de organisatie. Diversiteitsmanagement gaat over het managen en waarderen van verschillen om te komen tot betere organisatieresultaten (Wilson \& Iles, 1999; Pitts, 2005).

Een bestuurskundige blik helpt om deze theoretische perspectieven te begrijpen en toe te passen in de publieke context. Vanuit de theorie over representatieve bureaucratie is de relatie te leggen met de meerwaarde van diversiteit voor publieke organisaties. Net zoals de legitimiteitsinvalshoek gaat deze theorie ervan uit dat de overheid door de afspiegeling te zijn van de samenleving beter kan inspelen op de wensen en behoeften van haar burgers. Daar waar het bij de actieve representatie gaat om de individuele waarden van een ambtenaar in het werkveld (Krislov \& Rosenbloom, 1981), gaat het bij diversiteitsmanagement om het waarderen en managen van verschillen ten behoeve van de efficiëntie en effectiviteit van organisaties (Pitts, 2005; Groeneveld \& Van de Walle, 2010). 
Het verbindingsperspectief borduurt voort op alle hiervoor beschreven perspectieven. Het gaat verder dan de demografische weerspiegeling in de personeelssamenstelling en de bijdrage van diversiteit aan de effectiviteit van de overheid. Het verbindingsperspectief benadrukt de maatschappelijke opgaven van overheidsorganisaties. Van alle medewerkers wordt verwacht verbindingen te leggen met de diversiteit aan klanten, burgers en ook collega's. Het maken van verbindingen tussen overheid en burgers om maatschappelijke doelstellingen te realiseren, is daarmee een zaak van alle ambtenaren, los van hun etnische achtergrond. Het verbindingsperspectief benadrukt tevens de langetermijnrelatie tussen overheid en burger. Dit houdt in dat een divers samengesteld ambtelijk apparaat continu in contact staat met de samenleving, de verschillende belangen en verwachtingen inventariseert en begrijpt, en dit vertaalt naar overheidsbeleid. Zo investeert de overheid in een duurzame relatie met de burger. Dit verhoogt de responsiviteit van en daarmee ook het vertrouwen van burgers in de overheid.

\section{Conclusie en discussie}

Diversiteitsperspectieven zijn de motieven van organisaties om diversiteit in de organisatie te bevorderen. De perspectieven vormen het fundament van interventies die ontwikkeld en ingezet worden. Wanneer bestuurders, beleidsmakers en uitvoerders scherp in beeld hebben waarom zij werk willen maken van diversiteit en welke doelen zij ermee willen bereiken, dan bevordert dat hun integrale kijk op diversiteitsontwikkeling. Dan worden de diversiteitsambities sterker verbonden aan de organisatiedoelen. Door expliciet te maken wat publieke organisaties willen bereiken, kunnen ze beter interventies kiezen die passen bij dat doel. Als bijvoorbeeld voor een gemeente de legitimiteit vooropstaat, dan gaat het om de uitstraling. In dat geval is zichtbare diversiteit onder baliepersoneel dat direct in contact staat met burgers belangrijker dan in een backoffice. Als het gaat om creativiteit, dan is het niet relevant dat het personeel er divers uitziet, maar staat er een andere, vernieuwende inbreng centraal. Door het doel en de motieven scherper te hebben wordt het gemakkelijker interventies te kiezen om dat doel te bereiken.

Het verbindingsperspectief - een nieuw perspectief vanuit de bestuurskunde wint steeds meer aan belang, mede doordat het maatschappelijke klimaat de laatste jaren onmiskenbaar is verruwd en er steeds minder ruimte is voor het anderszijn. De toenemende polarisatie in de samenleving doet steeds meer een beroep op de verbindende rol van de overheid, ook om een kloof tussen de overheid en de burgers te voorkomen. Door een langetermijnrelatie met de burgers te onderhouden kunnen publieke organisaties bijdragen aan de realisatie van maatschappelijke doelstellingen. Door de verbinding met hen te verduurzamen groeit het vertrouwen van burgers in de overheid. Het verbindingsperspectief onderscheidt zich van de andere perspectieven op nog één belangrijk punt: het kunnen omgaan met verschillen in de samenleving wordt als een competentie gezien voor alle ambtenaren. Met andere woorden, niet alleen Hassan en Havva moeten verbin- 
dingen kunnen leggen met alle burgers, maar ook Hans en Hanna. Diversiteit is een onderwerp voor alle medewerkers. Bij de vormgeving van diversiteitsbeleid kunnen publieke organisaties veel meer de nadruk leggen op het verbindingsperspectief. De achterliggende gedachte van dit perspectief is dat het verbindend vermogen een belangrijke competentie is voor alle medewerkers. Met deze insteek kunnen organisaties buiten winnen door intern te beginnen. Dat wil zeggen dat de verbinding met de collega's onderling kan helpen om extern met de burgers de relaties te versterken. Met dit perspectief wordt bijgedragen aan een inclusieve organisatie, waarbij verschillen er mogen zijn en elkaar versterken. Iets van niet te onderschatten belang voor publieke organisaties, want als er sprake is van inclusie kunnen alle talenten tot hun recht komen.

\section{Literatuur}

Ashikali, T.S., Erradouani, F., \& Groeneveld, S.M. (2013). De meerwaarde van diversiteit in de publieke sector. De rol van diversiteitsbeleid, HRM en leiderschap . Rotterdam: Erasmus Universiteit Rotterdam.

Bailey, M. (2004). Representative bureaucracy: Understanding its past to address its future. Public Administration Review, 64(2), 246-249.

Bekkers, V.J.J.M. (2007). Beleid in beweging. Den Haag: Lemma.

Boselie, J.P.P.E.F. (2014). Strategic human resource management: A balanced approach (2nd edition). Maidenhaed: McGraw-Hill.

Çelik, S. (2016). Sturen op verbinden. De business case van diversiteit van publieke organisaties. Dissertatie, Universiteit Leiden, Leiden.

Çelik, S. (2018). Diversiteit, de gewoonste zaak van de wereld? Lectorale rede, Hogeschool Leiden, Leiden.

Çelik, S., \& Çelik, G. (2017). Aiming to connect: The business case for diversity in public organizations in the Netherlands. Public Money \& Management, 37(7), 499-506.

Çelik, S., \& Hopman, N. (2018). Leiderschapsdilemma's van burgemeesters in tijden van veranderingen. Bestuurswetenschappen, 72(3), 59-66.

Çelik, G., Vos, M., \& Vries, S. de. (2014). Verschil benutten in het hoger onderwijs: een integrale, interactieve en iteratieve benadering van organisatieontwikkeling. Tijdschrift voor Hoger Onderwijs, 32(4), 305-318.

Coleman Selden, S., Brudney, J.L., \& Kellough J.E. (1998). Bureaucracy as a representative institution: Towards a reconciliation of bureaucratic government and democratic theory. American Journal of Political Science, 42(3), 719-744.

Dolan, J., \& Rosenbloom, D.H. (2003). Representative bureaucracy: Classic readings and continuing controversies. Armonk, NY: M.E. Sharpe.

Ely, R.J., \& Thomas, D.A. (2001). Cultural diversity at work: The effects of diversity perspectives on work group processes and outcomes. Administrative Science Quarterly, 46(2), 229-273.

Frouws, B., \& Buiskool, B.J. (2010). Diversiteitsbeleid in internationaal perspectief. Een internationale vergelijking van diversiteitsbeleid in de publieke sector. Zoetermeer: Research voor Beleid.

Groeneveld, S.M., \& Steijn, B. (2013). Arbeidsmarkt, werving en selectie. In B. Steijn, \& S.M. Groeneveld (red.). Strategisch HRM in de publieke sector (pp. 77-102). Assen: Van Gorcum. 
Groeneveld, S.M., \& Van de Walle, S. (2010). A contingency approach to representative bureaucracy: Power, equal opportunities and diversity. International Review of Administrative Sciences, 76(2), 239-258.

Harrison, D.A., \& Klein, K.J. (2007). What's the difference? Diversity constructs as separation, variety, or disparity in organizations. Academy of Management Review, 32(4), 1199-1228.

Herring, C. (2009). Does diversity pay? Race, gender, and the business case for diversity. American Sociological Review, 74(2), 208-224.

Hooft, E.A.J. van. (2005). Diversiteit op de arbeidsmarkt en effectieve personeelswerving. Gids voor Personeelsmanagement, 84(3), 26-28.

Kellough, J.E., \& Naff, K.C. (2004). Responding to a wake-up call: An examination of federal agency diversity management programs. Administration Society, 36(1), 62-90.

Kirton, G., \& Greene, A. (2010). The dynamics of managing diversity: A critical approach. Oxford, Elsevier Butterworth-Heinemann.

Knippenberg, D. van, \& Schippers, M.C. (2007). Work group diversity. Annual Review of Psychology, 58, 515-541.

Kochan, T., Bezrukova, K., Ely, R., Jackson, S., Joshi, A., Jehn, K., Leonard, J., Levine, D., \& Thomas, D. (2003). The effects of diversity on business performance: Report of the diversity research network. Human Resource Management, 42(1), 3-21.

Krislov, S., \& Rosenbloom, D. (1981). Representative bureaucracy and the American political system. New York: Praeger.

Kwakkelstein, T., \& Roelse, V.E. (2011). De grote uittocht en HRM: van bedreiging naar kans. Tijdschrift voor HRM, 3, 7-26.

Maravić, P. von, Peters, B.G., \& Schröter, E. (Eds.). (2013). Representative bureaucracy in action: Country profiles from the Americas, Europe, Africa and Asia. Cheltenham: Edward Elgar.

Meer, F.M. van der, \& Dijkstra, G.S.A. (2013). Representative bureaucracy and diversity in the Netherlands. In B.G. Peters, P. von Maravić \& E. Schröter (Eds.), Representative bureaucracy in action. Country profiles from the Americas, Europe, Africa, and Asia (pp. 129-155). Cheltenham: Edward Elgar.

Mosher, F.C. (1968). Democracy and the public service. New York: Oxford University Press.

Pitts, D.W. (2005). Diversity, Representation, and Performance: Evidence about Race and Ethnicity in Public Administration. Journal of Public Administration Research and Theory, 15 (4), 615-631.

Pitts, D.W. (2009). Diversity management, job satisfaction, and performance: Evidence from U.S. federal agencies. Public Administration Review, 69(2), 328-338.

Regeerakkoord. (2017). Vertrouwen in de toekomst. Regeerakkoord 2017-2020. Regeerakkoord VVD, CDA, D66 en ChristenUnie.

Rijksoverheid. (2018). In het hart van de publieke zaak. Strategisch personeelsbeleid Rijk 2025. Den Haag.

Rob (Raad voor het openbaar bestuur). (2015). Sturen én verbinden. Den Haag.

Saltzstein, G.H. (1979). Representative bureaucracy and bureaucratic responsibility: Problems and prospects. Administration and Society, 10(1), 464-475.

Selden, S.C., \& Selden, F. (2001). Rethinking diversity in public organizations for the 21st century: Moving toward a multicultural model. Administration \& Society, 33(3), 303-329.

Selden, S.C., Brudney, J.L., \& Kellough, J.E. (1998). Bureaucracy as a representative institution: Toward reconciliation of bureaucratic government and democratic theory. American Journal of Political Science, 42(3), 719-744.

SER (Sociaal-Economische Raad). (2009). Diversiteit in het personeelsbestand. Den Haag. 
Shore, L.M., Randel, A.E., Chung, B.G., Dean, M.A., Ehrhart, K.H., \& Singh, G. (2011). Inclusion and diversity in work groups: A review and model for future research. Journal of Management, 37(4), 1262-1289.

Sowa, J.E., \& Selden, S.C. (2003). Administrative discretion and active representation. An expansion of the theory of representative bureaucracy. Public Administration Review, 63(6), 700-710.

Steijn, B., \& Groeneveld, S. (red.). (2013). Strategisch HRM in de publieke sector (2de druk). Assen: Koninklijke Van Gorcum.

Tanghe, J., Zee, K. van der, \& Postmes, T. (2010). Verkenning van effectieve interventies ter bevordering van arbeidsintegratie. In S. Otten, K. van der Zee \& J. Tanghe (red.), Werkt diversiteit? Arbeidsintegratie en vertrouwen in een kleurrijke samenleving (pp. 71-87). Groningen: Instituut voor Integratie en Sociale Weerbaarheid.

Verbeek, S. (2012). Diversity policies and ethnic minority representation. Dissertatie, Erasmus Universiteit Rotterdam, Rotterdam.

Wilson, E.M., \& Iles, P.A. (1999) Managing diversity: An employment and service delivery challenge. International Journal of Public Sector Management, 12(1), 27-49. 